\title{
Tafonomia de Tempestitos Conchíferos Amalgamados da Formação Teresina em Rio Preto (Estado do Paraná, Permiano Médio, Bacia do Paraná) e suas Implicações Paleoambientais
}

\author{
Taphonomy of Condensed Shell Storm beds of the Teresina Formation in Rio Preto \\ (State of Paraná, Middle Permian, Paraná Basin): Paleoenvironmental Implications
}

\author{
Jacqueline Peixoto Neves¹ (nevesjp.unesp@gmail.com), Rosemarie Rohn Davies² (rohn@rc.unesp.br), \\ Marcello Guimarães Simões ${ }^{1}$ (profmgsimoes@gmail.com) \\ ${ }^{1}$ Departamento de Zoologia - Instituto de Biociências - UNESP \\ Distrito de Rubião Jr. s/n, CEP 18618-000, Botucatu, SP, BR \\ ${ }^{2}$ Departamento de Geologia Aplicada - IGCE - UNESP, Rio Claro, SP, BR
}

Recebido em 12 de julho de 2011; aceito em 19 de outubro de 2011

\begin{abstract}
RESUMO
Depósitos da Formação Teresina são tipicamente caracterizados por rochas siliciclásticas finas, com frequentes intercalações submétricas de tempestitos carbonáticos ou siliciclásticos (arenitos bioclásticos e coquinas). Estudos tafonômicos em rochas carbonáticas ainda são muito escassos, apesar de sua peculiar relevância em estudos paleoambientais. A concentração de conchas aqui estudada localiza-se em uma pedreira do município de Irati, distrito de Rio Preto/PR, possivelmente correspondente ao intervalo médio a superior da Formação Teresina, porém ainda distante do topo. A camada estudada, classificada como grainstone/packsone bioclástico-intraclástico-peloidal, é constituída por abundantes fragmentos de bivalves, intraclastos pelíticos e micríticos, peloides, raros ooides e oncoides, além de micrófilos permineralizados de licófitas e escamas de peixe. Trata-se um exemplo de acumulação carbonática cujos grãos evidenciam: elevado grau de mistura temporal; empacotamento variável entre denso e disperso; baixa seleção e estão, predominantemente, caóticos. A concentração apresenta uma mescla de elementos gerados em condições ambientais distintas: a) ambientes carbonáticos restritos de baixa energia (peloides, ooides com córtex espesso e oncoides); b) ambientes emersos próximos ao corpo d'água (micrófilos de licófitas) e c) ambientes calmos, porém pontuados por eventos de tempestades, onde viviam bivalves escavadores, suspensívoros. Na camada, podem ser discriminados pelo menos quatro episódios deposicionais controlados por fluxos combinados de tempestades, gerada em condições de baixa subsidência da bacia e mergulhos extremamente baixos do assoalho oceânico.
\end{abstract}

Palavras-chave: Bacia do Paraná; Permiano; Grupo Passa Dois; Carbonato; Moluscos Bivalves; Tempestito.

\begin{abstract}
The deposits of the Permian Teresina Formation are mainly characterized by fine-grained siliciclastic rocks and centimetric intercalations of tempestites (bioclastic sandstones and coquinas). Despite the relevance of the bivalve-rich carbonate beds of the Teresina Formation to paleoenvironmental studies, their taphonomy is still poorly studied. The fossil concentration studied in this work was found in a quarry in the city of Irati, Rio Preto district, Paraná State. The fossil concentration is located in the middle/upper portion of the unit, far from the top. The studied bed is a bioclastic, intraclastic, peloidal, grainstone/ packstone, with abundant bivalve shell fragments, pelitic and micritic intraclasts, peloids, rare ooids and oncoids, as well as permineralized of Lycophyta microphylles and fish scales. The grains of this carbonate concentration show: high degree of time-averaging, variable degree of packing (dense to disperse), no sorting and chaotic orientation. Notably, the concentration includes a mixture of elements which are indicative of: a) restrictive, low energy, carbonate environment (peloids, ooids and oncoids); b) subaerial environment surrounding the main body of water (Lycophyta microphylles) and c) quiet-water environment punctuated by storm events, where the suspension-feeding bivalves thrived. At least four depositional events caused by storm flows were recorded. The amalgamated nature of the bed is a result of storm events in an intracratonic basin with very low seafloor slope and low rates of sedimentation and subsidence.
\end{abstract}

Keywords: Parana Basin; Permian; Passa Dois Group; Carbonate; Bivalve mollusk; Tempestite. 


\section{INTRODUÇÃO}

Na sucessão permiana da Bacia do Paraná espessos pacotes de rochas siliciclásticas se alternam com discretos depósitos carbonáticos, conforme bem exemplificado pelo registro sedimentar do Grupo Passa Dois (formações Irati, Serra Alta, Teresina e Rio do Rasto, além da Formação Corumbataí no norte da bacia). Os carbonatos mais amplamente estudados dessa sucessão são, sem dúvida, os pertencentes à Formação Irati (Mendes, 1962; Hachiro, 1991, 1997; Lages, 2004). Por outro lado, as rochas carbonáticas da Formação Teresina começaram a merecer análises petrográficas detalhadas há poucos anos, principalmente na região central a nordeste do Estado do Paraná e sul do Estado de São Paulo (Petri e Coimbra, 1982; Sousa, Suguio, Castro, 1991; Rohn, 1994, 2001, 2007; Castro et al., 2001; Lourenço, 2003; Rohn, Lourenço, Meglhioratti, 2003; Meglhioratti, 2005, 2006; Ng, 2010). Moluscos bivalves são os fósseis mais comuns das rochas carbonáticas da formação.

Até o momento, não foram bem esclarecidas as relações verticais e laterais entre as rochas carbonáticas e as siliciclásticas, nem as condições paleoambientais, paleogeográficas, tectônicas, paleoclimáticas, diagenéticas e, provavelmente, biológicas que controlaram a sua gênese. Adicionalmente, já são históricas as discussões, em parte apenas semânticas, sobre o caráter possivelmente "marinho", "parálico" ou "continental" dessa unidade, pois os organismos aquáticos preservados são fósseis questionáveis como indicadores de habitats marinhos normais.

Através de análise tafonômica, uma complexa camada carbonática da Formação Teresina no distrito de Rio Preto, no município de Irati (PR), oferece oportunidade para discutir questões sedimentológicas, paleoecológicas e estratigráficas. A caracterização de tal camada integra um estudo tafonômico mais amplo sobre concentrações conchíferas das formações Teresina e Rio do Rasto (Neves, 2009; Neves, Rohn, Simões, 2010).

\section{Caracterização Sintética da Formação Teresina e de Situações Tafonômicas Previamente Conhecidas}

A Formação Teresina, na região central a norte do Estado do Paraná, apresenta cerca de $300 \mathrm{~m}$ de espessura. Nessa unidade, as rochas siliciclásticas são predominantemente constituídas por sedimentos de fração granulométrica fina, em grande parte, fácies heterolíticas com acamamento flaser/wavy/lenticular de folhelhos cinza e arenitos muito finos interlaminados, geralmente bioturbados e, às vezes, com gretas de contração, e fácies de arenitos finos com laminações cruzadas por ondas ou estratificação cruzada hummocky (Lavina, 1991; Rohn, 1994). As fácies siliciclásticas normalmente ocorrem organizadas como sucessões granocrescentes ( $\sim 0,5 \mathrm{a} \sim 6 \mathrm{~m}$ de espessura), com delgados folhelhos escuros basais, frequentemente arenitos decimétricos - prováveis tempestidos - na parte superior e, na parte intermediária, equivalendo à maior parte da sucessão, rochas heterolíticas com aumento ascendente da proporção de lâminas areníticas (Rohn, 2001; Lourenço, 2003; Rohn, Lourenço, Meglhioratti, 2003 e Meglhioratti, 2005, 2006). Cada sucessão granoascendente representa um ciclo de "raseamento", podendo receber distintas denominações ("parassequência", "PAC" etc.; Rohn, 2001), porém foge ao escopo do presente estudo discutir os modelos estratigráficos.

As sucessões siliciclásticas cíclicas observadas em testemunhos de sondagens parecem ser correlacionáveis por dezenas de quilômetros. A grande continuidade lateral das fácies é típica dos mares epêiricos das bacias cratônicas, ou seja, de um corpo d'água muito raso com assoalho praticamente plano (Rohn, 2001; Lourenço, 2003; Rohn, Lourenço, Meglhioratti, 2003; Meglhioratti, 2005, 2006).

Os estratos carbonáticos, por sua vez, apresentam espessuras que variam de alguns milímetros até $\sim 3 \mathrm{~m}$, normalmente entre 20 e $40 \mathrm{~cm}$, destacando-se bioesparitos, biomicritos, biolititos estromatolíticos e algumas brechas carbonáticas (Petri e Coimbra, 1982; Sousa, Suguio, Castro, 1991; Rohn, 1994, 2001, 2007; Castro et al., 2001; Lourenço, 2003; Rohn, Lourenço, Meglhioratti, 2003; Meglhioratti, 2005, 2006; Ng, 2010). Os fósseis mais comuns são moluscos bivalves, encontrados também em arenitos bioclásticos (Mendes, 1952; Simões e Kowalewski, 1998) e coquinas (Mendes, 1952; Simões, Torello, Rocha-Campos, 1996).

Os carbonatos comumente estão intercalados como camadas discretas entre as sucessões cíclicas siliciclásticas. Excepcionalmente, em alguns intervalos ( $10 \mathrm{~m})$, a proporção de camadas carbonáticas praticamente sobrepuja a de siliciclastos (Rohn, 2001, 2007). Tais intervalos, a exemplo das sucessões siliciclásticas, são correlacionáveis ao longo de dezenas ou centenas de quilômetros através de perfis geofísicos de poços. Contudo, estudos detalhados dos testemunhos de poços, assim como correlações entre afloramentos próximos, revelaram que as fácies carbonáticas propriamente ditas dos intervalos variam lateralmente ou até desaparecem localmente (Rohn, 2007).

Estudos tafonômicos de coquinas e arenitos coquinoides da Formação Corumbataí no Estado de São Paulo (lateralmente equivalente, em parte, à Formação Teresina dos estados sulinos da Bacia do Paraná), demonstraram que diversos depósitos representam tempestitos proximais amalgamados, onde os bioclastos foram submetidos a uma apreciável mistura temporal, possivelmente durante períodos da ordem de $10^{2}$ a $10^{4}$ anos (Simões, Torello, Rocha-Campos, 
1996; Simões e Kowalewski, 1998; Simões e Torello, 2003). Situação similar foi constatada na Formação Teresina em grainstones oolíticos a bivalves de Prudentópolis/ PR (Neves, 2009; Neves, Rohn, Simões, 2010) e também na parte inferior da Formação Rio do Rasto em packstones/wackestones oncolíticos a bivalves de Ribeirão Claro/ PR (Neves, 2009). É provável que a gênese de diversas outras camadas carbonáticas do Grupo Passa Dois tenha envolvido um período de tempo bastante longo de retrabalhamento dos bioclastos (vide Klein e Simões, 1998; Simões e Torello, 2003).

\section{MATERIAL E MÉTODOS}

As rochas carbonáticas aqui estudadas foram coletadas em pedreira localizada a sudoeste de Irati, aproximadamente no centro-sul do município homônimo, na estrada Irati/ Rio Preto (Figura 1), cerca de $3 \mathrm{~km}$ antes da última localidade e $0,7 \mathrm{~km}$ a oeste da ponte sobre o rio Corrente, nas coordenadas UTM 22J 0525,29 km E/7176,88 km N, à altitude (na base) de aproximadamente $840 \mathrm{~m}$. Essa pedreira ainda ativa tem uma frente de cava com cerca de $30 \mathrm{~m}$ de extensão e outra ortogonal, com $20 \mathrm{~m}$ e altura máxima de $22 \mathrm{~m}$.

Em campo, foram realizadas observações qualitativas, com especial atenção à espessura, continuidade lateral, geometria, contatos, grau de empacotamento e assinaturas tafonômicas dos bioclastos, conforme sugerido por Kidwell e Holland (1991), Simões e Kowalewski (1998) e Simões e Ghilardi (2000). Não foi possível coletar um bloco abrangendo o intervalo vertical completo da camada fossilífera, dada sua espessura e dureza. Entretanto, foram coletadas várias amostras representativas de toda a extensão vertical, de modo que, posteriormente, foi possível reconstituir sua posição original na camada.

Em laboratório, as amostras foram preparadas de acordo com as recomendações de Feldmann, Chapman e Hannibal (1989). Posteriormente, foram encaminhadas para a preparação de lâminas delgadas, a partir das quais foram realizadas análises de microfácies em microscópio de luz polarizada, observando feições e estruturas microscópicas da camada, como morfologia e tipos de grãos, conteúdo fossilífero, cimento e feições diagenéticas. Conjuntamente, os atributos tafonômicos foram descritos com base em trabalhos clássicos: Kidwell, Fürsich e Aigner (1986), Brett e Baird (1986), Fürsich e Oschman (1986, 1993) e Kidwell e Holland (1991). Para a classificação genética das concentrações fossilíferas, os critérios obedeceram Kidwell (1991) e Fürsich e Oschmann (1993) e para as rochas carbonáticas, Dunham (1962). Finalmente, para a identificação das conchas de moluscos bivalves que ocorrem na camada de Rio Preto, foi empregada a sistemática sugerida por Runnegar e Newell (1971).
Os exemplares de conchas e de micrófilos de licófitas separadas da matriz encontram-se no acervo do Museu de Paleontologia e Estratigrafia Prof. Dr. Paulo Milton Barbosa Landim do IGCE/UNESP, Campus de Rio Claro, catalogados como URC.MB.307. Amostras da camada estudada e as lâminas petrográficas fazem parte do acervo do UNESPetro na UNESP - Rio Claro (URC.MB. 425-430), havendo fatias das mesmas amostras no acervo no Laboratório de Paleozoologia Evolutiva do IBB/UNESP - Botucatu (LT DZP 575-591). Uma amostra da rocha com um oncoide faz parte do acervo do IGc/USP (GP/6E-217) e foi gentilmente emprestada pelo Prof. Dr. Thomas R. Fairchild.

\section{DESCRIÇÃO DO AFLORAMENTO E DA CAMADA CONCHÍFERA}

Na exposição de Rio Preto predominam rochas siliciclásticas finas, principalmente rochas heterolíticas constituídas por folhelhos cinza e arenitos muito finos interlaminados, com acamamento flaser, wavy e lenticular (Figura 2), como na maior parte da Formação Teresina. Os folhelhos predominam em relação aos arenitos e aparecem alterados como finas pastilhas. Apenas um pouco acima da porção média da exposição, observa-se um nítido intervalo granocrescente $(\sim 3,5 \mathrm{~m})$ de arenitos nas rochas heterolíticas.

São especialmente notórias grandes gretas de contração no piso da pedreira, bem como vegetais fósseis nos siltitos sobrepostos às gretas. Entre os vegetais destacam-se delicadas e abundantes briófitas, até o momento, encontradas somente neste afloramento da Formação Teresina, além de oogônios de algas carófitas (Rösler, 1982; Rohn, 1994; Faria e Ricardi-Branco, 2009).

Nos siliciclastos ocorrem três intercalações carbonáticas submétricas, situadas na parte inferior, média e superior da pedreira (Figuras 2 e 3A). A média, que constitui o objeto do presente trabalho, aparentemente é a única fossilífera. As principais feições macroscópicas encontram-se ilustradas na Figura 3 e as microscópicas, na Figura 4.

Foram identificadas as seguintes espécies de moluscos bivalves: Pinzonella neotropica, Jacquesia elongata, Pyramus anceps e Ferrazia cardinalis (Figura 5). Alguns espécimes foram encontrados rolados próximos à camada estudada e outros foram coletados por Rohn (1994) no mesmo local.

A camada conchífera é tabular ao longo da exposição da pedreira, apresentando espessura em torno de $45 \mathrm{~cm}$ (Figura 3B). A camada sobrepõe uma sucessão de rochas heterolíticas, mas não de modo totalmente abrupto, pois uma delgada camada $(1 \mathrm{~cm})$ com a mesma composição já aparece ligeiramente abaixo da camada principal $(\sim 1,0-1,5 \mathrm{~cm}$ abaixo), intercalada concordantemente ao acamamento wavy das rochas heterolíticas (Figura 3D). A camada conchífera 


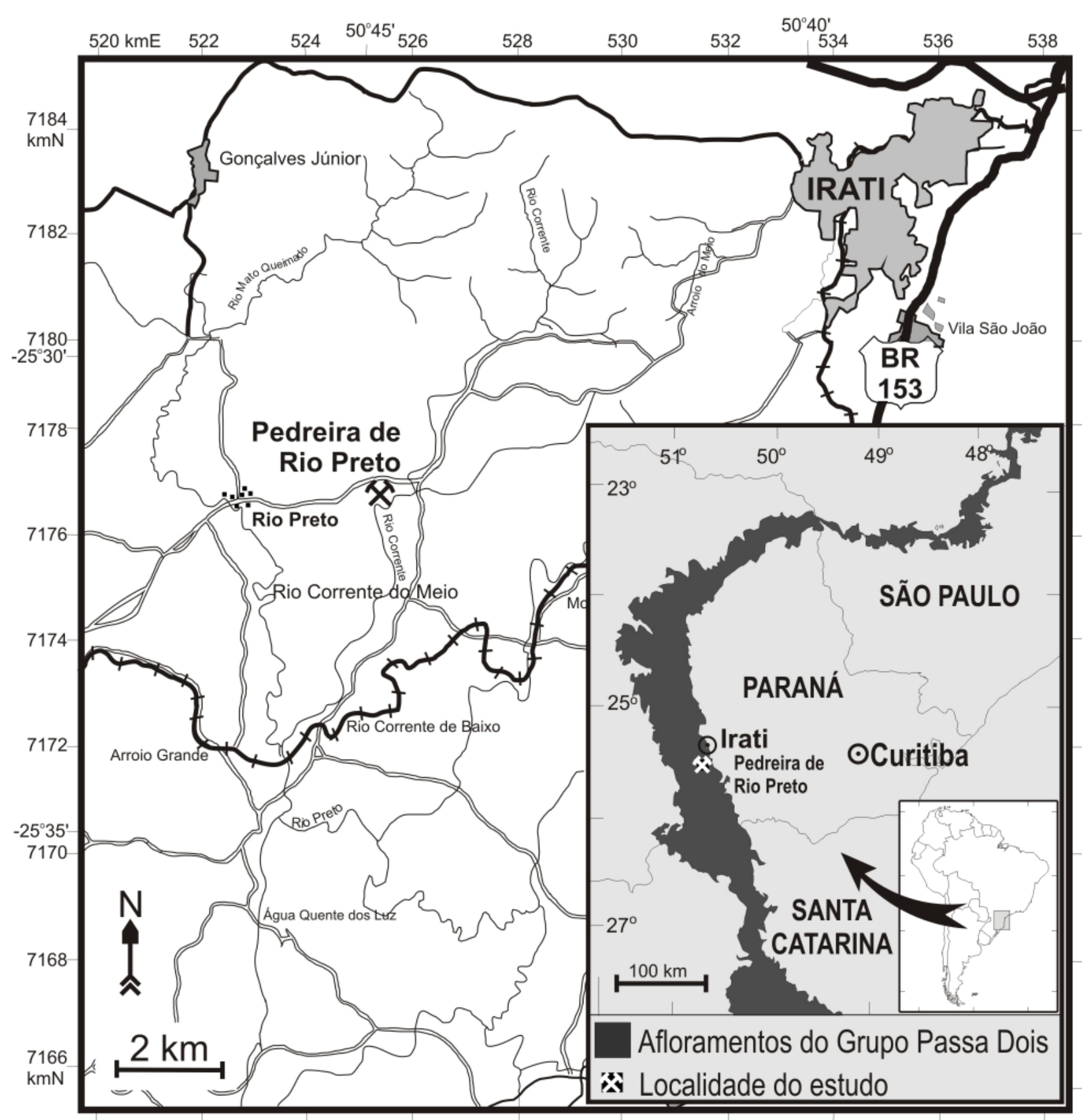

Figura 1. Localização da pedreira de Rio Preto.

propriamente dita trunca o último delgado intervalo heterolítico através de uma superfície de erosão aproximadamente plana, o que é corroborado pela presença de pequenos intraclastos argilosos na sua porção basal.

A camada carbonática conchífera foi classificada como grainstone/packstone bioclástico-intraclástico-peloidal de acordo com a nomenclatura de Dunham (1962), pois é suportada por grãos, principalmente bioclastos, intraclastos e peloides (Figura 4D), além de grãos oolíticos, oncolíticos e terrígenos. A franja de esparito que se desenvolveu em torno da maioria dos grãos substancia a designação grainstone. Por outro lado, alguns espaços preenchidos por pseudosparito formado a partir de micrito, admitem a classificação secundária da rocha como packstone. 


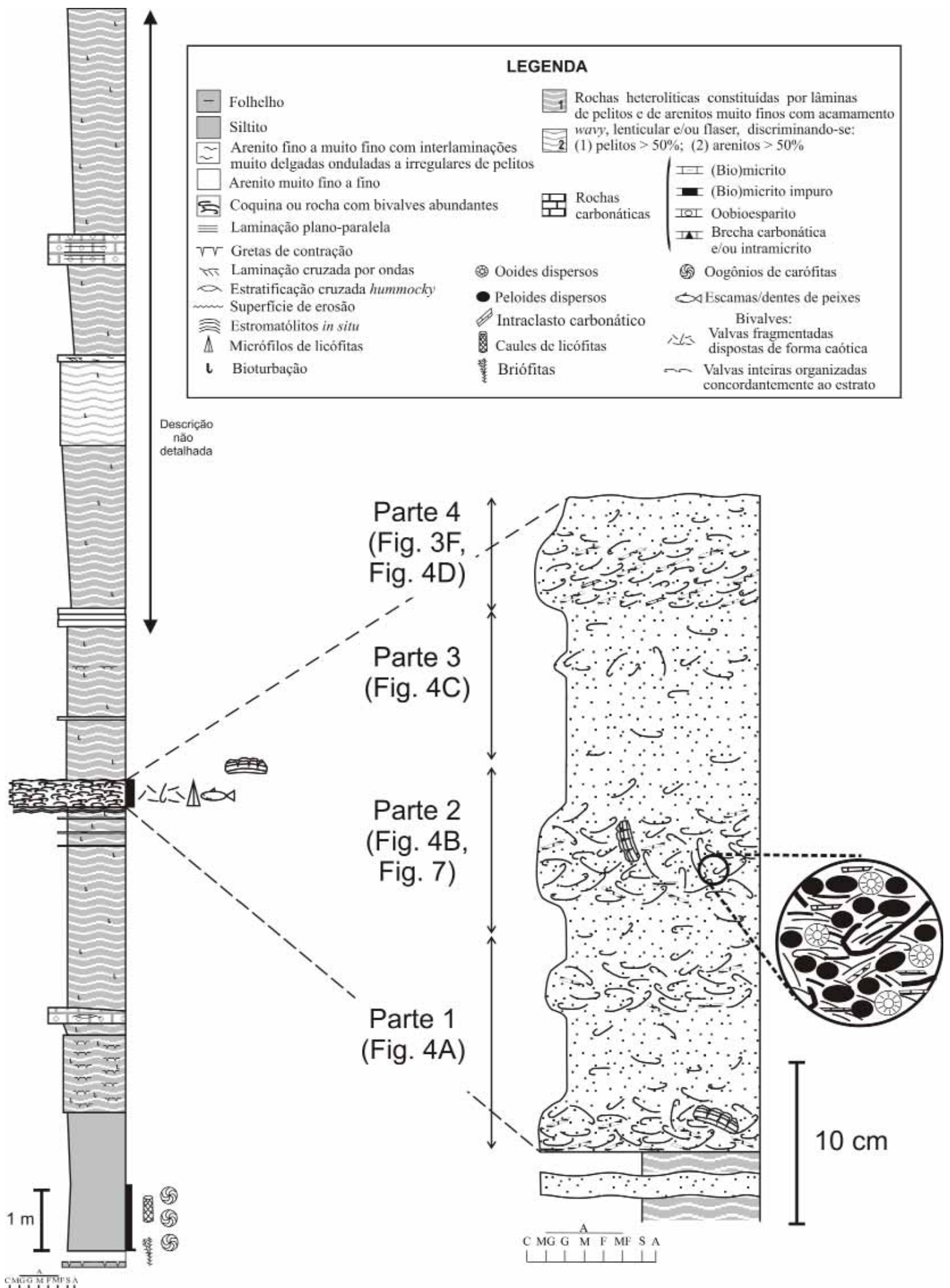

Figura 2. Perfil colunar do afloramento de Rio Preto, PR, Formação Teresina. 

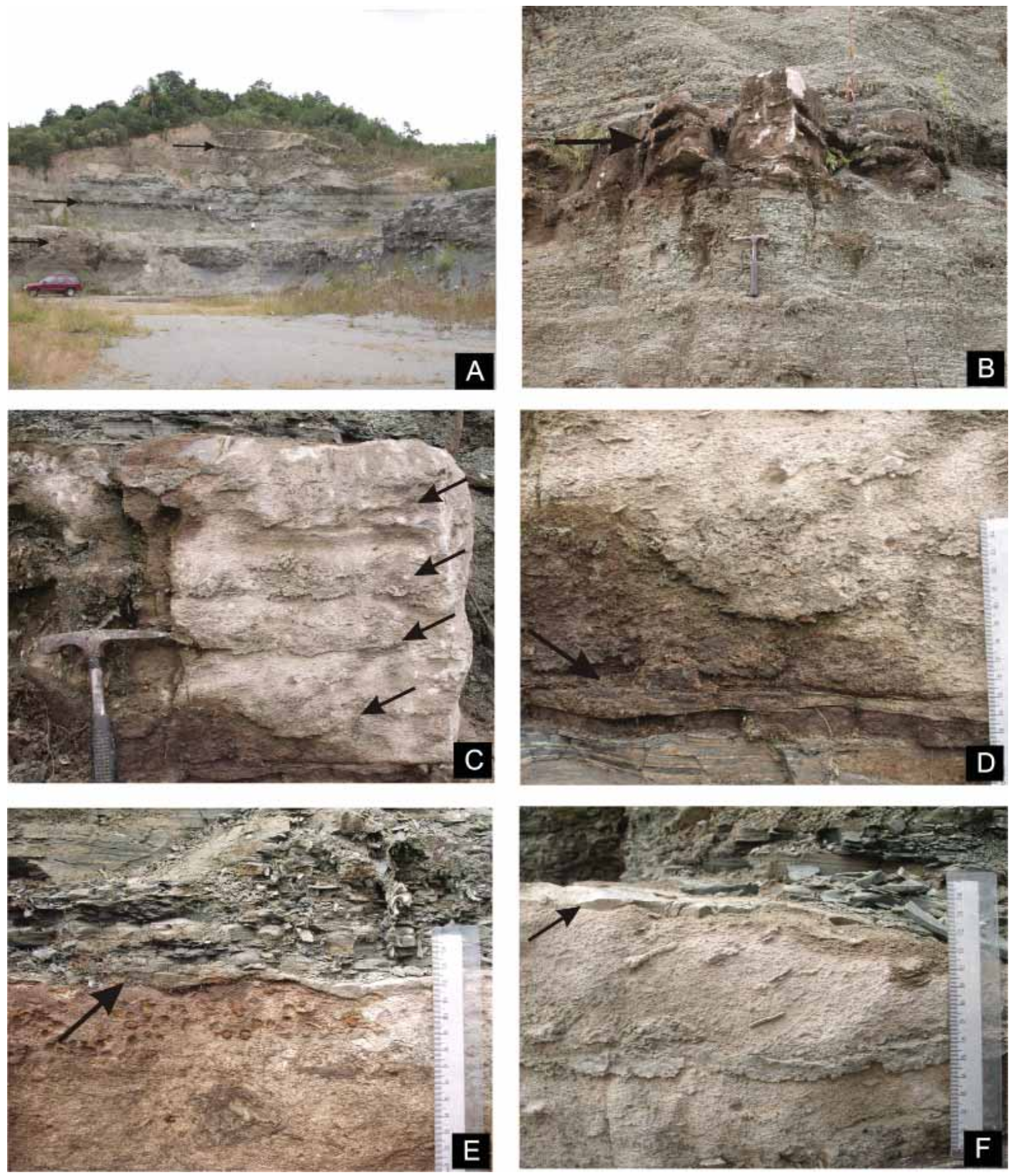

Figura 3. A. Afloramento da pedreira de Rio Preto mostrando três camadas carbonáticas (setas), das quais a central é fossilífera e constitui o foco do presente trabalho. B. Camada carbonática estudada destacada entre as rochas siliciclásticas (arenitos e folhelhos interlaminados com acamamento wavy, empastilhados devido alteração intempérica). C. Exposição vertical ligeiramente intemperizada da camada estudada, onde aparece ressaltada a alternância entre regiões com empacotamentos distintos dos bio- e intraclastos na rocha carbonática. Topo suavemente ondulado. D. Passagem ascendente da rocha siliciclástica para a carbonática estudada, observando-se entre estas uma delgada camada carbonática, seguida por uma delgada siliciclástica (seta). Escala (régua) $=15 \mathrm{~cm}$. E. Superfície de erosão (seta) e possíveis ondulações entre a camada carbonática e a rocha siliciclástica sobrejacente. Escala em centímetros. F. Estratificação cruzada na parte superior da camada carbonática em Rio Preto sugerida pela orientação oblíqua dos intraclastos e bioclastos. Escala em centímetros. 

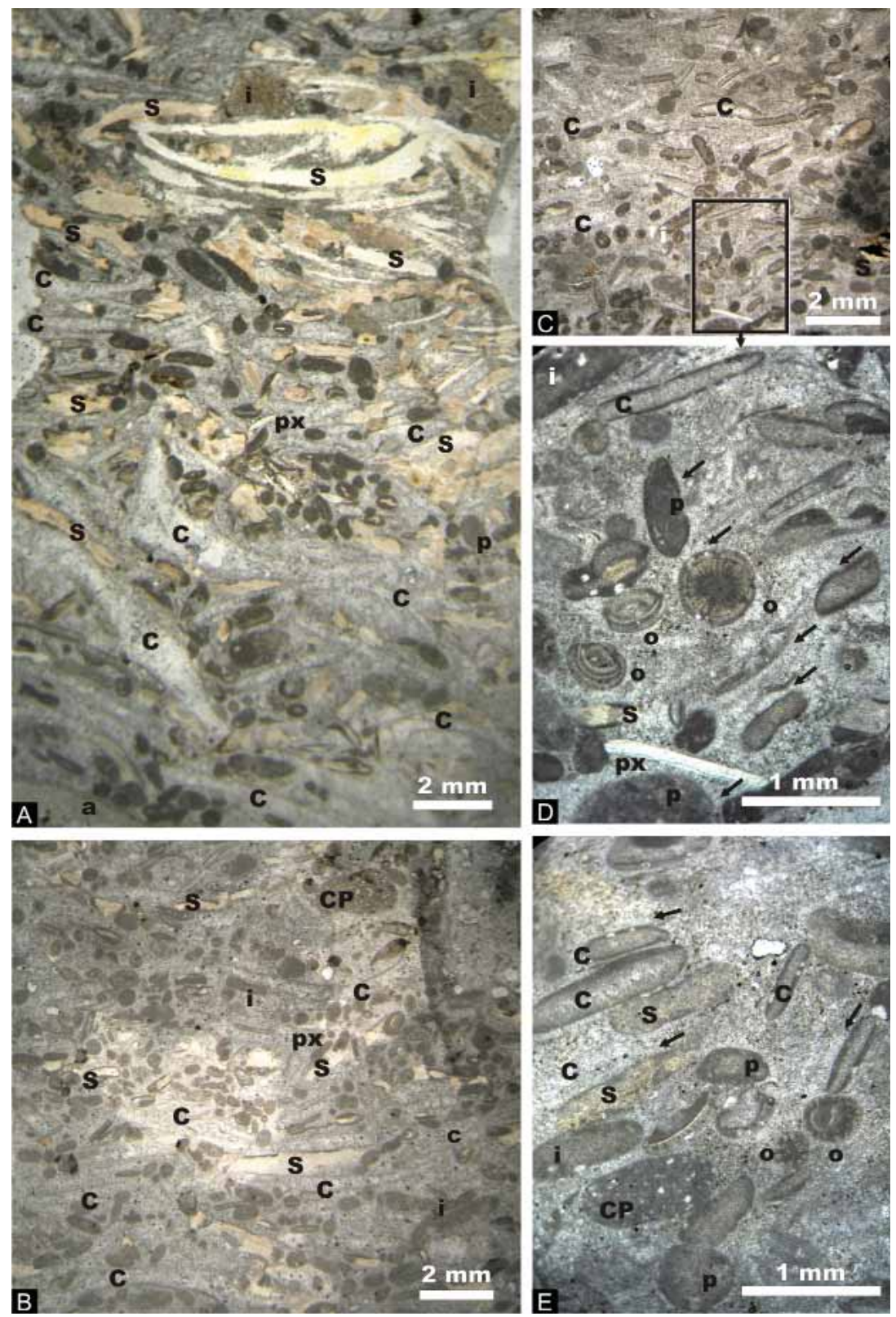

Figura 4. Grainstone/packstone bioclástico-intraclástico-peloidal de Rio Preto ao microscópio petrográfico, com nicois paralelos, topo apontando para cima. Tipos de grãos indicados: $\mathrm{C}=$ concha "recristalizada"; $\mathrm{S}=$ concha ou outro fóssil silicificado; $a$ = clasto de argilito; $\mathrm{i}=$ intraclasto carbonático; $\mathrm{px}=$ bioclasto fosfático, provavelmente resto de peixe; $\mathrm{CP}=$ possível coprólito; $\mathrm{o}=$ ooide; $\mathrm{p}=$ peloide; setas = esparita radial envelopando grãos. A. Porção basal da camada, mostrando parte de um clasto de argilito no canto esquerdo inferior da foto, conchas relativamente grandes de calcita "recristalizada" ou silicificadas, as últimas em proporção relativamente alta. O rientação das conchas variável: em algumas porções com arranjo oblíquo e imbricamentos, em outras porções sub-horizontal, e localmente caótica. B. Porção média a superior da camada (Parte 3 superior na figura 2). Em comparação à parte inferior (Figura 4A), proporção bem maior de peloides e de conchas "recristalizadas" e fragmentadas, em disposição levemente oblíqua irregular; grãos menores com distribuição heterogênea e arranjo caótico. C. Porção superior da camada (Parte 4 da Figura 2). Predominância de fragmentos de conchas pequenos. Parte inferior com empacotamento denso dos grãos, em disposição localmente oblíqua, misturados com grãos em posições caóticas; gradação ascendente para empacotamento menos denso e disposição mais caótica dos grãos. D. Detalhe da Figura 4C, mostrando ooide com padrão predominantemente radial, dois ooides mal-desenvolvidos com núcleos aparentemente de ostracodes; fragmento fosfático atribuível a peixe. E. Parte superior da camada. Destaque para possível coprólito, fragmentos de conchas "recristalizadas" com bordos fortemente micritizados e arredondados; outros sem bordos micritizados, confundindo-se com a matriz. Arranjo paralelo oblíquo dos grãos alongados. 
As conchas de bivalves são os constituintes aloquímicos mais comuns (Figura 4C, E). Estão predominantemente fragmentadas, às vezes com arestas ligeiramente arredondadas, mas existem algumas valvas completas sem evidências de abrasão. Os fragmentos podem ser da ordem de milímetros, sendo difícil distingui-los, a olho nu, dos outros grãos. As maiores conchas alcançam, aproximadamente, 3 cm de comprimento (conforme medidas nos cortes verticais das amostras), mas seus tamanhos são bem variáveis. Análises petrográficas revelam que quase todas as conchas são compostas por cristais de calcita e apresentam bordas escuras micritizadas (espessuras $\sim 5 \mu \mathrm{m}$ ) (Figura 4E). Alguns fragmentos de conchas estão silicificados (Figura 4A), possuem superfície ligeiramente irregular que denota corrosão e também bordas mais escuras.

Os ooides caracterizam-se por calcita cristalizada radialmente, forma nem sempre esférica, podendo ser bastante irregular, e diâmetro médio de 0,6 mm (Figura 4B). Os abundantes peloides apresentam formas arredondadas, porém irregulares, com granulação na fração areia fina, em média 0,9 mm de diâmetro (Figura 4C). Alguns grãos escuros, similares aos peloides, possuem manchas circulares esbranquiçadas e podem corresponder a coprólitos.

Misturados com os grãos carbonáticos ocorrem grãos de quartzo da granulação areia fina a silte e abundantes intraclastos, pelíticos ou micríticos, geralmente placoides e angulosos, às vezes arredondados, normalmente subcentimétricos, excepcionalmente alcançando $5 \mathrm{~cm}$ de comprimento. Diversos intraclastos confundem-se, à primeira vista, com os pequenos fragmentos de conchas devido às dimensões similares, especialmente a pequena espessura, mas são "lascas" planas e não curvas como os bivalves.

Raras conchas foram incrustadas por esteiras microbiais, especialmente sobre a superfície convexa das valvas, tendo originado oncoides que alcançam cerca de $3 \mathrm{~cm}$ de comprimento (Figura 6A).

Bioclastos adicionais da camada de Rio Preto são raros dentes e escamas de peixes (Figura 4A), cuja composição fosfática original foi mantida, e fragmentos de micrófilos de licófitas e outros pequenos restos vegetais permineralizados por sílica (Figura 6B).

Na parte superior da camada ocorrem frequentes cristais de pirita ou pequenos nódulos ferruginosos que devem corresponder a grãos de pirita alterados (Figura 3C).

Conforme os critérios de Kidwell e Holland (1991) para descrições tafonômicas macroscópicas, um bioclasto "grosso" seria todo fóssil ou fragmento de fóssil maior do que $2 \mathrm{~mm}$. Partículas menores do que $2 \mathrm{~mm}$ fariam parte da "matriz" (incluindo grãos, lama carbonática e/ou cimento). No presente trabalho, preferiu-se denominar esta massa mais fina simplesmente como "fração $<2$ mm", evitando-se eventual confusão com o significado do termo "matriz" na nomenclatura das rochas carbonáticas. Desta forma, quando se analisa o empacotamento e a seleção dos bioclastos numa rocha, somente os fósseis maiores do que $2 \mathrm{~mm}$ são analisados.

Genericamente, foram discriminadas na camada em estudo, quatro variações verticais no empacotamento das conchas (Figura 3B). Suas espessuras aproximadas, em ordem ascendente, são: 7 - $8 \mathrm{~cm}$; 9 - $10 \mathrm{~cm} ; 18-19 \mathrm{~cm} ; 8-9 \mathrm{~cm}$. O terceiro intervalo, conforme o local da observação, pode estar subdividido em dois, (com $13-14 \mathrm{~cm}$ e $4-5 \mathrm{~cm}$ ). No perfil idealizado da Figura 2, as partes 1 a 4 indicadas não se referem à compartimentação natural da camada, mas à sucessão de amostras coletadas, cujas respectivas lâminas estão ilustradas na Figura 4.

Os três primeiros intervalos começam com empacotamento médio (onde os bioclastos constituem cerca de $25 \%$ do volume da rocha) seguido por empacotamento frouxo (onde os bioclastos constituem menos do que 5\% do volume da rocha; Kidwell e Holland, 1991), havendo ligeira gradação entre as duas porções. De um intervalo para o outro também ocorrem passagens relativamente graduais e irregulares entre as porções mais densamente empacotadas e as mais frouxamente empacotadas, além de existirem porções silicificadas aproximadamente horizontais que dificultam a visualização.

As porções que possuem os empacotamentos mais densos incluem as maiores conchas e intraclastos, embora sejam bastante variáveis quanto às dimensões. Exceto no intervalo superior, o arranjo das valvas é caótico e ocorrem situações de aninhamentos de conchas.

Na porção superior do primeiro intervalo, em lâmina petrográfica, observou-se uma pequena região circular caracterizada por organização mais ou menos concêntrica de grãos, devendo representar uma minúscula escavação de organismo.

Diversas porções silicificadas da camada coincidem com aquelas onde ocorrem os empacotamentos mais densos. No terceiro intervalo, quase inteiramente representado na Figura 7, a silicificação ocorreu preferencialmente acima da porção mais densamente empacotada, a qual excepcionalmente ultrapassa $6 \mathrm{~cm}$ de espessura.

O intervalo superior começa com empacotamento aparentemente mais denso que os outros intervalos (talvez $40 \%$ de bioclastos em relação ao volume da rocha), o tamanho das conchas normalmente é menor, as valvas encontram-se preferencialmente orientadas com a superfície côncava para cima, mas também ligeiramente oblíquas ou com imbricamentos, intraclastos são mais abundantes e dispostos obliquamente, ocorre ligeira tendência de granodecrescência ascendente e, conforme o local da observação da camada, é possível reconhecer estratificação cruzada de baixo ângulo (Figura 3F). 


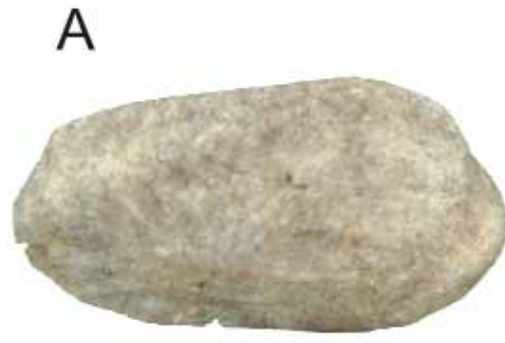

C

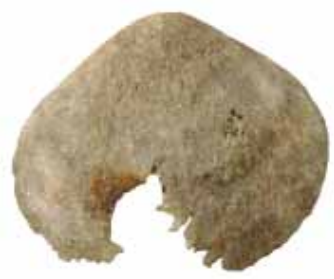

B

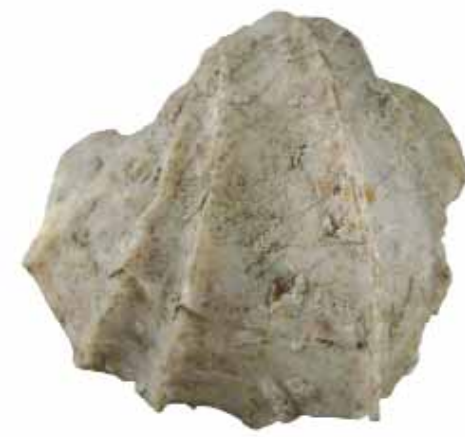

D

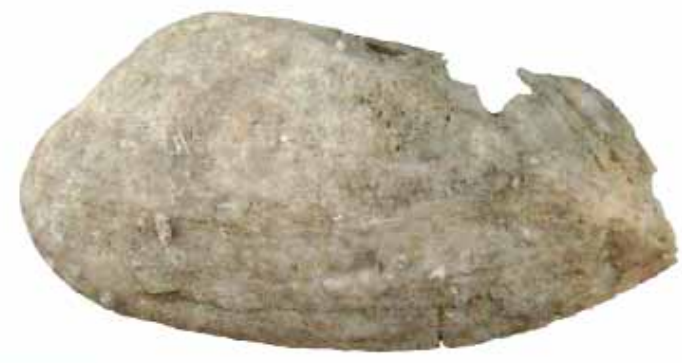

\section{$1 \mathrm{~cm}$}

Figura 5. Bivalves da pedreira Rio Preto. A. Pinzonella neotropica, valva direita. B. Ferrazia cardinalis, valva direita. C. Pyramus anceps, valva direita. D. Jacquesia elongata, valva esquerda. Todas as conchas estão silicificadas.

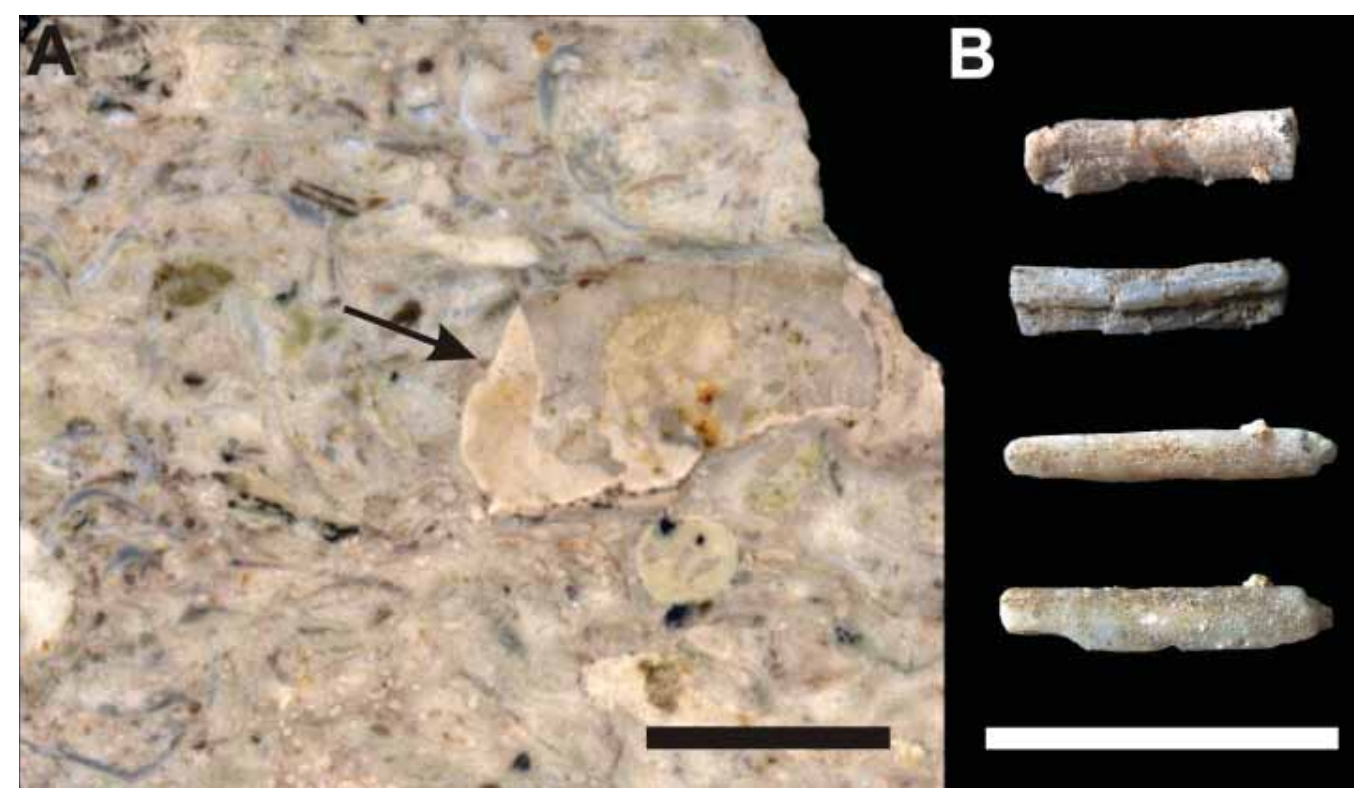

Figura 6. A. Corte vertical da camada de Rio Preto com oncoide (seta) incrustado sobre concha de bivalve, parcialmente silicificado; escala $=1 \mathrm{~cm}$. B. Fragmentos de micrófilos de licófitas permineralizados por sílica extraídos do calcário estudado, escala $=0,5 \mathrm{~cm}$. 

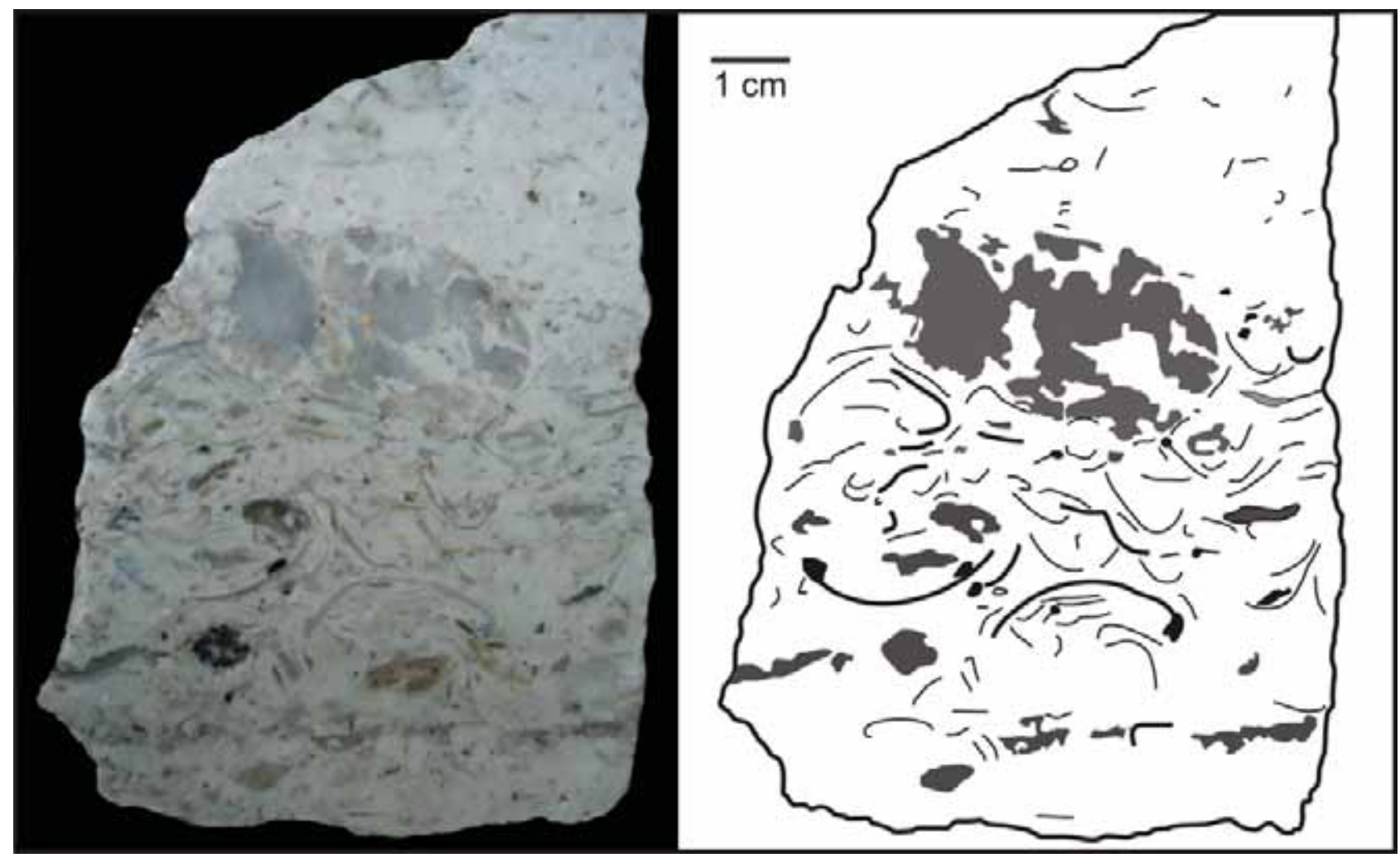

Figura 7. Foto e respectivo esquema de seção vertical da parte 2 da camada de Rio Preto (vide Figura 2), mostrando duas porções com empacotamento de conchas frouxo separadas por intervalo mais densamente empacotamento com valvas isoladas fragmentadas ou inteiras, mal selecionadas, em disposição caótica. Partes silicificadas representadas em cinza.

O topo da camada possui tênues ondulações, seguindo-se passagem abrupta para rochas heterolíticas similares àquelas abaixo da camada.

\section{DISCUSSÃO}

O afloramento de Rio Preto tem posição estratigráfica incerta, pois se encontra praticamente isolado, sem afloramentos diagnósticos nas proximidades. Os bivalves Pinzonella neotropica, Jacquesia elongata e Pyramus anceps, permitem inferir sua posição na Zona Pinzonella neotropica - a biozona mais alta no âmbito da Formação Teresina. Por outro lado, a espécie Ferrazia cardinalis é mais típica da biozona sotoposta (Rohn, 1994, 2007). Licófitas, oncoides e restos de peixes são comuns na formação, porém não têm importância na determinação da posição estratigráfica da camada estudada. Julga-se que o afloramento de Rio Preto esteja num intervalo médio a superior da Formação Teresina, porém ainda distante do topo.

Acumulações de conchas de bivalves nas formações Teresina e Corumbataí são tipicamente preservadas em tempestitos, na forma de arenitos bioclásticos (Simões e Kowalewski, 1998), coquinas (Simões, Torello, Rocha-Campos, 1996; Simões e Torello, 2003) e calcarenitos (Rohn, 1994, 2001; Castro et al., 2001; Lourenço, 2003; Meglhioratti, 2005, 2006; Neves, 2009; Neves, Rohn, Simões, 2010). Por exemplo, em Prudentópolis/PR, na porção média da Formação Teresina ocorrem grainstones oolíticos a bivalves, com grandes ondulações e gretas de contração no topo (Castro et al., 2001; Neves, 2009; Neves, Rohn, Simões, 2010).

É importante ressaltar que a Formação Teresina se originou num "mar" interior epêirico (i.e., muito raso, com centenas de quilômetros de extensão), em geral hidrodinamicamente muito calmo, onde o dia-a-dia era caracterizado pela sedimentação de partículas muito finas, principalmente siliciclásticas. Os tempestitos representam os únicos registros de episódios de alta energia na história deposicional (vide Lavina, 1991; Rohn, 1994, 2001; Simões, Torello, Rocha-Campos, 1996; Simões e Kowalewski, 1998; Castro et al., 2001; Simões e Torello, 2003).

A camada de Rio Preto certamente corresponde a mais um registro de sedimentação controlada por tempestade, 
considerando-se a granulação relativamente grossa dos seus constituintes (em comparação à granulação muito fina das camadas adjacentes), sua disposição caótica, as variações verticais na concentração dos bioclastos/clastos, a baixa seleção granulométrica, o topo da camada tendendo a ondulado e a presença local de estratificação cruzada de baixo ângulo - possivelmente atribuível a uma estratificação hummocky.

A importância da camada de Rio Preto vai muito além do reconhecimento de que se trata de um corpo gerado sob a influência de tempestade. A concentração demonstra um enorme grau de mistura temporal, dada a grande diversidade de grãos encontrados. A análise microfaciológica mostrou que muitos dos grãos na camada de Rio Preto foram gerados em ambientes distintos.

A primeira evidência de tal mistura é a presença de bivalves ecologicamente incompatíveis em uma mesma acumulação, ainda que devam ter pertencido à uma comunidade de infauna rasa, suspensívora, como a maioria dos bivalves das formações Teresina e Corumbataí (Simões, Rocha-Campos, Anelli, 1998; Ghilardi, 1999; Anelli, Simões, David, 2010; Simões, Anelli, David, 2010). A morfologia funcional de Ferrazia cardinalis indica hábito escavador raso, lento e que, preferencialmente, colonizava substratos de granulometria areia (Ghilardi, 1999; Simões e Ghilardi, 2000). Por outro lado, Pyramus anceps é uma forma escavadora rápida, que deveria ter ocupado substrato lamoso (Ghilardi, 1999; Simões e Ghilardi, 2000). Portanto, a ocorrência conjunta das espécies indica uma associação tafonômica e não natural.

As conchas da camada de Rio Preto, dado o grau variado de fragmentação, sugerem história tafonômica complexa. No dia-a-dia, em condições de águas calmas normais, as valvas dos organismos mortos das biocenoses eram gradualmente incorporadas ao substrato lamoso ou arenoso. Sua concentração deve ter variado conforme a taxa de reprodução dos bivalves, taxa de sedimentação e o tempo de acumulação. Eventos de alta energia hidráulica provavelmente foram responsáveis por exumar ocasionalmente valvas já incorporadas ao substrato. Conforme as condições de energia do meio, as conchas podem ter sido colocadas em suspensão, senão transportadas por tração, e os choques entre elas devem ter sido responsáveis por sua fragmentação. Na recorrência dos processos, formaram-se não só grãos cada vez menores como também foi gerada lama carbonática, provavelmente num intervalo de tempo relativamente longo.

Segundo Flügel (1982), as bordas escuras em conchas seriam comuns em depósitos marinhos e representariam porções micritizadas devido intensas microperfurações por microorganismos, como fungos e algas endolíticas. Os cristais de calcita das conchas não representariam um simples processo de recristalização, mas a dissolução da aragonita original da concha e precipitação de calcita, com manutenção da forma externa original graças à resistência da borda micritizada à dissolução (Tucker e Wright, 1990; Flügel, 1982; Tucker, 1992).

Porém, o que realmente diferencia a camada de Rio Preto de outras camadas carbonáticas conchíferas do Grupo Passa Dois (vide Neves, 2009) é a grande quantidade intraclastos e peloides misturados aos bioclastos, além de ooides e eventuais oncoides, como explicado a seguir.

Peloides são grãos destituídos de estruturas internas, diferentemente de ooides e oncoides, e apresentam formas variáveis. Segundo Flügel (2004), existem nove tipos de peloides, que diferem entre si com relação à sua gênese. $\mathrm{O}$ tipo comumente encontrado na camada estudada é o chamado "peloide de lama", com forma irregular a subarredondada, cuja origem está associada à micritização de grãos carbonáticos (micro e criptocristalinos) que se formam pelo retrabalhamento de lama carbonática litificada e/ou clastos micríticos. Rangel (2002), fundamentado no trabalho de Barthust (1971), inferiu que peloides são grãos comumente encontrados em ambientes protegidos, como lagunas ou em plataformas internas. Flügel (2004) concorda que peloides são tipicamente retrabalhados e redepositados em ambientes marinhos rasos protegidos. Alguns grãos semelhantes a peloides, mas com manchas circulares esbranquiçadas podem corresponder a pelotas fecais ou coprólitos.

Ooides constituídos de fibras radiais com córtex espesso, como os encontrados aqui (Figura 4 B) são característicos de ambientes marinhos rasos calmos, pontuados por episódios de maior energia, geralmente em condições restritas, diferentemente de ooides com laminações concêntricas que são gerados em ambientes marinhos muito rasos e de alta energia (Flügel, 2004).

Os oncoides na camada de Rio Preto são raros, mas relativamente grandes. Assemelham-se a outras ocorrências no Grupo Passa Dois, em Joaquim Távora (Rohn e Fairchild, 1986), Ribeirão Claro (Meglhioratti, 2006; Neves, 2009) e em algumas camadas observadas em furos de sondagem (Lourenço, 2003; Meglhioratti, 2005, 2006). As comunidades microbianas incrustaram preferencialmente as superfícies convexas de valvas - possivelmente o único substrato disponível para a colonização em águas calmas e rasas, com provável fundo lamoso. Não há registros preservados dos sítios de desenvolvimento dos oncoides, pois estes também foram transportados e misturados com os demais grãos nos eventos de sedimentação da camada de Rio Preto. Tendo em vista as dimensões dos oncoides, as condições de energia para o seu transporte devem ter sido significativas.

A grande quantidade de intraclastos distribuídos entre os fragmentos de bivalves evidencia provável remoção de sedimentos gretados, e mistura com os demais grãos. $\mathrm{Na}$ Formação Teresina, gretas de contração são comuns 
tanto nas rochas heterolíticas siliciclásticas (com acamamento wavy), quanto em rochas carbonáticas finas, desde porções próximas à paleoborda da bacia, quanto em áreas mais centrais (Rohn, 2001; Lourenço, 2003; Meglhioratti, 2006 etc.). A exposição subaérea dos sedimentos finos promovia a formação de pequenas pastilhas semiconsolidadas; posteriormente, quando o nível d'água voltava a subir ou por invasão de áreas secas durante as tempestades, as pastilhas eram retrabalhadas. Os intraclastos de argilitos observados próximo à base da camada estudada podem derivar das rochas heterolíticas sotopostas, talvez semiconsolidadas ou previamente gretadas. Outros intraclastos, em partes mais superiores da camada, são pastilhas predominantemente micríticas e derivam, portanto, de um sítio de acumulação de lama carbonática, provavelmente exposto e gretado. $\mathrm{O}$ tamanho relativamente grande de alguns intraclastos $(\sim 5 \mathrm{~cm})$ indica que dificilmente procederam de locais muito distantes. Os finos grãos de quartzo misturados indicam que sítios de sedimentação carbonática e siliciclástica podem ter sido coevos, pouco distantes entre si e "varridos" pelos fluxos relacionados às tempestades.

Finalmente, cabem alguns comentários sobre os outros bioclastos. As escamas de peixe e os ostracodes certamente representam organismos que viviam no ambiente deposicional. Até o momento, não existem publicações específicas sobre as características petrográficas de tais fósseis da Formação Teresina. Em estudos paleontológicos convencionais, restos de peixes e ostracodes têm fornecido resultados controversos sobre paleoambientes e idades.

A presença de micrófilos de licófitas permineralizados por sílica misturados às conchas e a outros grãos tem importantes implicações. As licófitas registradas na Formação Teresina foram vegetais provavelmente herbáceos a arbustivos de regiões costeiras que tinham abscisão natural dos micrófilos, designados formalmente como Lepidophylloides corumbataensis (Faria e Ricardi-Branco, 2010). $\mathrm{O}$ fato de que os micrófilos ocorrem como fragmentos tridimensionais retilíneos misturados com outros bio- ou intraclastos grossos indica que tiveram comportamento hidráulico similar e, portanto, já estavam permineralizados antes de terem sido incorporados ao depósito carbonático. Caso contrário, os micrófilos teriam sido deformados entre as conchas ou nem teriam depositado junto com os grãos mais pesados, já que teriam ficado muito mais tempo em suspensão. O processo da permineralização pode ter sido facultado nos vegetais depositados em corpos d'água costeiros que se tornavam sazonalmente muito alcalinos $(\mathrm{pH}$ $>10$ ) devido à intensa evaporação, quando a sílica entrava em solução e impregnava os tecidos vegetais (vide Tavares e Rohn, 2009). Situação similar de micrófilos em coquina retrabalhados após a permineralização foi registrada Formação Teresina em Canoinhas/ SC (Rohn, 1994).
Em suma, considerando-se a incompatibilidade genética dos grãos da camada de Rio Preto, nenhum é autóctono e pouquíssimos poderiam ser parautóctonos (sensu Kidwell, Fürsich, Aigner, 1986). A formação da camada envolveu múltiplos eventos de fundo (background events). Os fósseis de distintas origens misturados representam uma mistura temporal desarmoniosa (vide Simões e Kowalewski, 1998).

Nas tempestades normalmente ocorrem fluxos combinados de ondas e correntes geradas por fortes ventos (Harms, 1969; Walker e Plint, 1992; Vierek, 2010). Os fluxos combinados são responsáveis por estratificações cruzadas hummocky, laminações horizontais e cruzadas. Também podem ocasionar a deposição de bio e intraclastos alongados em posições verticais, conforme o movimento orbital que controla o aumento ou a diminuição do atrito dos clastos com o fundo (Mount e Kidder, 1993; Vierek, 2010). Kidwell e Bosence (1991), entre diversos outros autores (e.g., Liu e Greyling, 1996; Anderson e McBride, 1996; Bressan e Palma, 2010), mencionaram que biotramas caracterizadas por conchas em posições caóticas resultariam de fluxos turbulentos de alta densidade ou correntes e ondas combinadas que causariam interferência entre abundantes conchas em suspensão antes da rápida deposição. Quando as conchas e outros grãos em suspensão se depositam, formam-se gradações granodecrescentes, ou seja, com as maiores conchas e os empacotamentos mais densos na porção basal. Ao contrário, quando o processo deposicional é por tração, as conchas ficam orientadas com a superfície convexa para cima ou imbricadas (Anderson e McBride, 1996). A camada de Rio Preto, portanto, enquadra-se no primeiro caso. A má seleção dos grãos, inclusive a mistura de grandes oncoides com sedimentos muito finos, é uma evidência adicional de que os processos deposicionais envolveram suspensão de sedimentos em alta concentração, em condições de alta energia e rápida deposição.

Dadas as considerações anteriores, as variações no empacotamento das conchas desde a base até o topo da camada de Rio Preto refletem variações nas condições hidráulicas. Diversos autores (e.g., Aigner, 1984; Kidwell, 1991; Radley e Barker, 2000; Bressan e Palma, 2010; entre outros) descreveram camadas conchíferas internamente complexas que possuem uma sucessão de gradações de empacotamentos de conchas densos para frouxos. Aigner (1984) denominou as camadas gradadas como graded skeletal sheets. Cada intervalo gradado tem sido atribuído a um episódio de tempestade distinto. Sedimentos finos bioturbados eventualmente separam os distintos tempestitos (e.g., Radley e Barker, 2000), mas também existe a possibilidade de completa amalgamação (e.g., Kidwell, 1991; Bressan e Palma, 2010). No caso de Rio Preto, não foram preservados sedimentos finos entre os intervalos que devem representar as distintas tempestades e apenas próximo ao topo do primeiro intervalo há suspeita 
de bioturbação. Provavelmente, os bioclastos e outros grãos depositados em cada episódio ainda ficavam relativamente soltos (não cimentados entre si) até o episódio deposicional seguinte. Desta forma, muitas conchas previamente depositadas eram novamente retrabalhadas, mascarando os limites entre as sucessivas acumulações.

O último intervalo da camada de Rio Preto distingue-se um pouco dos demais, lembrando que há intraclastos orientados obliquamente sugestivos de estratificação cruzada de baixo ângulo, empacotamento mais denso de conchas, seleção ligeiramente melhor, tendência a dimensões menores e orientação preferencialmente com a superfície côncava para cima. Tais características permitem interpretar que na combinação de ondas e correntes unidirecionais no evento de tempestade, ou seja, processos combinados de suspensão e tração, as correntes tiveram importância ligeiramente maior, mas ainda não o suficiente para selecionar bem os grãos, nem para orientar as valvas com a superfície convexa para cima.

Conforme já comentado, a rocha é suportada por grãos e tem cimento esparítico, mas algumas porções intergranulares possuem pseudoesparito derivado de micrita. Esta micrita pode ter infiltrado entre os grãos depois de cada episódio deposicional de alta energia, já que teria decantado muito mais lentamente, como uma "cauda" em suspensão pós-tempestade (e.g., Liu e Greyling, 1996). Também é possível que parte dos grãos carbonáticos tenha sofrido completa micritização posterior, o que não é incomum neste tipo de acumulação carbonática (El-Sammak, 2001; Saner, Babalola, Abdulghani, 2005).

A camada de Rio Preto não revela retroalimentação tafonômica, que seria a interação de novos bivalves com as conchas já depositadas, pois a composição taxonômica de bivalves aparentemente é constante da base ao topo da camada, sem evidência de substituição das espécies escavadoras de substrato mole por espécies epifáunicas de substrato duro. Este fato corrobora a hipótese de que os bivalves são alóctonos.

Diversos episódios de retrabalhamento por tempestades registrados numa única camada, como no caso de Rio Preto, são explicáveis pela baixíssima subsidência da bacia intracratônica. Se a taxa de subsidência tivesse sido maior ou em condições muito mais distais do sítio de sedimentação, ter-se-ia, no mínimo, uma camada pelítica (da sedimentação normal, sem tempestade, do dia-a-dia) entre cada tempestito. Outro fator que facultou repetidos retrabalhamentos foi o mergulho extremamente baixo do assoalho da bacia. A melhor evidência do assoalho quase plano é a presença de gretas de contração não só em áreas que eventualmente teriam sido marginais (vide discussão abaixo), como também em amplas áreas interiores da bacia (conforme testemunhos de poços em Rohn, 1994; 2001). Portanto, o caráter amalgamado da camada de Rio Preto condiz com sítios deposicionais "proximais", mas não obrigatoriamente próximos à costa.

Segundo Pöppelreiter e Aigner (2005), as antigas bacias intracratônicas tinham mergulhos tão suaves que as faixas costeiras ultrapassavam uma centena de quilômetros em largura. Variações do nível da água da ordem de centímetros já causavam exposição ou afogamento de grandes áreas. Nas faixas costeiras, a água era tão rasa que ondas e correntes eram "abafadas" devido ao atrito com o fundo; ocorria deposição apenas de pelitos. Somente muito longe da costa iniciava-se a influência de fluxos induzidos por tempestades - que eram os processos de alta energia predominantes em mares epêiricos de bacias cratônicas. Se este modelo for válido para a Bacia do Paraná, pode-se inferir que uma extensa faixa lamosa mais costeira tenha sido (quase) totalmente erodida, ainda que possa ter sido bem irregular, com inúmeros golfos, e ter "migrado" lateralmente por centenas de quilômetros conforme as variações relativas do nível de base (transgressões/regressões). Regiões ligeiramente mais altas no assoalho da plataforma, possivelmente moldadas por fluxos de tempestades, podem ter constituído ilhas quando o nível relativo da água abaixava, talvez até com a colonização por vegetais tolerantes como licófitas. Os suaves bancos mais rasos tornavam-se eventualmente barreiras que separavam sítios deposicionais carbonáticos e siliciclásticos. Fluxos induzidos por tempestades misturavam esporadicamente os sedimentos dos distintos sítios.

Fases climáticas mais secas provavelmente promoviam expansão dos sítios carbonáticos em relação aos siliciclásticos, pois a diminuição de chuvas provavelmente implicava numa diminuição no aporte de siliciclastos, além de mudanças químicas da água (Rohn, 2001, 2007). Por outro lado, em tais fases mais secas, o nível d'água do mar interior provavelmente abaixava e amplas regiões sofriam exposição subaérea e/ou erosão, com a produção de abundantes intraclastos carbonáticos. Grandes gretas de contração em lamas carbonáticas devem refletir tais fases (Rohn, 1994). A camada carbonática de Rio Preto pode estar relacionada a um período mais seco, mas provavelmente não foi submetida à exposição subaérea, pois não há indícios de carstificação ou dissolução. O término da sedimentação carbonática de Rio Preto deu-se com o aporte de finos siliciclastos ao sítio deposicional, em condições de águas ligeiramente mais profundas e calmas, provavelmente quando retornaram condições climáticas mais úmidas.

\section{SUMÁRIO DAS OBSERVAÇÕES TAFONÔMICAS E COMENTÁRIOS FINAIS}

O grainstone/packstone bioclástico-intraclástico-peloidal de Rio Preto representa uma associação tafonômica mais complexa do que outras acumulações de conchas 
anteriormente descritas da Formação Teresina, tendo em vista a mistura de peloides, ooides, oncoides, micrófilos de licófitas, escamas de peixes, clastos pelíticos, grãos de quartzo, além das conchas de bivalves em distintos estados de fragmentação, gerados, em grande parte, em ambientes calmos, pontuados por episódios de maior energia. O depósito evidencia, portanto, intensa mistura temporal ocorrida sob influência de tempestades. De acordo com variações no empacotamento de conchas e biotrama da camada estudada, pode-se interpretar que pelo menos quatro episódios de tempestade participaram em sua gênese por fluxos combinados de ondas e correntes. Nos três primeiros intervalos, gradações de empacotamentos médios de valvas mal selecionadas e caóticas para empacotamentos frouxos indicam participação predominante de processos de suspensão na sedimentação. No último intervalo, estratificação cruzada de baixo ângulo, melhor seleção, empacotamento mais denso e orientação mais regular de valvas com superfície côncava para cima sugerem maior participação de correntes na sedimentação.

Ressalta-se que na Bacia do Paraná, os processos relacionados a tempestades geraram camadas conchíferas tanto siliciclásticas (e.g., arenitos bioclásticos, Simões e Kowalewski, 1998), quanto carbonáticas. Tempestitos conchíferos carbonáticos complexamente amalgamados foram descritos em detalhe, até o momento, somente em Prudentópolis (Neves, Rohn, Simões, 2010) e no presente caso de Rio Preto. O caráter extremamente amalgamado da concentração estudada reflete, em maior ou menor grau, a condição rasa do lago/mar da Bacia do Paraná, com baixíssimas taxas de sedimentação. Trata-se do mesmo padrão já observado para outras ocorrências de invertebrados em mares epicontinentais do Paleozoico e do Mesozoico.

\section{AGRADECIMENTOS}

Os autores expressam sinceros agradecimentos ao CNPq (Proc. 135018/2007) e à Fapesp (Proc. 07/57892-0) pelo apoio financeiro; a Paulo Tibana (UNESPetro/Núcleo de Petrologia Carbonática-NOPEC), pelo auxílio nas análises petrográficas; a Christiano Ng e Juliana Machado David pela contribuição nos trabalhos de campo e à Suzana Aparecida Matos da Silva pelo auxílio nas atividade de laboratório. Os professores Dimas Dias-Brito e Joel Carneiro de Castro (UNESPetro/Núcleo de Petrologia Carbonática-NOPEC) teceram comentários importantes nas versões iniciais desse manuscrito, aos quais os autores agradecem.

\section{REFERÊNCIAS}

AIGNER, T. Dynamic stratigraphy of epicontinental carbonates, Upper Muschelkalk (M. Triassic), South-
German Basin. Neues Jahrbuch fur Mineralogie, Geologie und Palaontologie. Abhandlungen, v. 169, n. 2, p. 127-159, 1984.

ANDERSON, L. C.; MCBRIDE, R. A. Taphonomic and paleoenvironmental evidence of Holocene shell-bed genesis and history on the Northeastern Gulf of Mexico shelf. Palaios, v. 11, p. 532-549, 1996.

ANELli, L. E.; SIMÕES, M. G.; DAVID, J. M. A new Permian bivalve (Megadesmidae, Plesiocyprinellinae) from the Serrinha Member (Rio do Rasto Formation) looking for a sedimentary strata. Geologia USP. Série Científica, v. 10, p. 13-21, 2010.

BARTHUST, R. C. G. Carbonate sediments and their diagenesis. Amsterdam: Elsevier Scientific, 1971. 620 p.

BRESSAN, G. S.; PALMA, R. M. Taphonomic analysis of fossil concentrations from La Manga Formation (Oxfordian), Neuquén Basin, Mendoza Province, Argentina. Journal of Iberian Geology, v. 36, n. 1, p. $55-71,2010$.

BRETT, C. E.; BAIRD, G. C. Comparative taphonomy: a key to paleoenviromental interpretation based on fossil preservation. Palaios, Tulsa, v. 4, p. 303-309, 1986.

CASTRO, J. C.; ROHN, R.; CASTRO, M. R.; TOLEDO, C. E. V. Camadas de tempestito grosso (coarse grained storm beds): exemplos do Permiano da bacia do Paraná. Revista Escola de Minas, Ouro Preto, v. 54, n. 3, p. 179-184, 2001.

DUNHAM, R. J. Classification of carbonate rocks according to depositional texture. Memoir AAPG, v. 1, p. 108-121, 1962.

EL-SAMMAK, A. A. Nature and genesis of silt-size carbonate sediments, northern Red Sea, Egypt. Carbonates and Evaporites, v. 16, n. 1, p. 37-45, 2001.

FARIA, R. S.; RICARDI-BRANCO, F. Leonardosia langei Sommer (Charophyta, Porocharaceae) from Corumbataí Formation (Guadalupian), Piracicaba, SP, Brazil; first record of an antheridium and of corticated thalli Ameghiniana, v. 46, n. 1, p. 49-57, 2009.

FARIA, R. S.; RICARDI-BRANCO, F. S. Lepidophylloides corumbataensis sp. nov. from the Guadalupian in the Paraná Basin, southern Brazil. Review of Paleobotany and Palynology, v. 160, p. 135-142, 2010. 
FELDMANN, R. M.; CHAPMAN, R. E.; HANNIBAL, J. T. Paleotechiques. Tennesse: The Paleontologycal Society Special Publications, 1989. 358 p. (Special publication; n. 4).

FLÜGEL, E.. Microfacies analysis of limestones. Berlim: Springer-Verlag, 198. 633 p.

FLÜGEL, E. Microfacies of carbonate rocks. Analysis, interpretation and application. Berlim: Springer Verlag, 2004. 976 p.

FURSICH, F. T.; OSCHMANN, W. Storm shell beds of Nanogyra virgule in the Upper Jurassic of France. Neues Jahrbuch fur Mineralogie, Geologie und Palaontologie. Abhandlungen, v. 172, p. 141-161, 1986.

FURSICH, F. T.; OSCHMANN, W. Shell beds as tool in basin analysis: The Jurassic of Kachchh, western Índia. Journal of the Geology Society, London, v. 150, p. $169-185,1993$.

GHILARDI, R. P. Paleoautoecologia dos bivalves do Grupo Passa Dois (Neopermiano) no Estado de São Paulo: bivalves fósseis como indicadores da dinâmica sedimentar. 1999. 160 f. Dissertação (Mestrado em Geologia Sedimentar) - Instituto de Geociências, Universidade de São Paulo, São Paulo, 1999.

HARMS, J. C. Hydraulic significance of some sand ripples. Geological Society of American Bulletin, v. 80, p. 363-396, 1969.

HACHIRO, J. Litótipos, associações faciológicas e sistemas deposicionais da Formação Irati no Estado de São Paulo. 1991. 175 f. Dissertação (Mestrado) Instituto de Geociências, Universidade de São Paulo, São Paulo, 1991.

HACHIRO, J. O Subgrupo Irati (Neopermiano) da Bacia do Paraná. 1997. 196 f. Tese (Doutorado) - Instituto de Geociências, Universidade de São Paulo, São Paulo, 1997.

KIDWELL, S. The stratigraphy of shell concentrations. In: ALliSON, P. A.; BRIGGS, D. E. G. Taphonomy: Releasing Data/Locked in the Fossil Record. - Topics in Geobiology. New York: Plenum Press, 1991. p. 211-290.

KIDWELL, S. M.; BOSENCE, D. W. J. Taphonomy and time-averaging of marine shelly faunas. In: ALLISON, P. A.; BRIGGS, D. E. G. Taphonomy, Releasing the Data Locked in the Fossil Record). New York: Plenum Press. 199. p. 115-209.
KIDWELL, S. M.; HOLLAND, S. M. Field description of coarse bioclastics fabrics. Palaios, Tulsa, v. 6, p. 426-434, 1991.

KIDWELL, S. M; FURSICH, F. T; AIGNER, T. Conceptual framework for the analysis of fossil concentrations. Palaios, Tulsa, v. 1, p. 228-238, 1986.

KLEIN, C.; SIMÕES, M. G. Tafonomia de Pelecípodes da Formação Terezina (Permiano), Tiarajú, RS, Brasil. Anais da Academia Brasileira de Ciência, v. 70, p. 619-625, 1998.

LAVINA, E. L. Geologia sedimentar e paleogeografia do Neopermiano e Eotriássico (Intervalo KazanianoScythiano) da Bacia do Paraná. 1991. 2 v. Tese (Doutorado) - Instituto de Geociências, Universidade Federal do Rio Grande do Sul, Porto Alegre, 1991.

LAGES, L. C. A Formação Irati (Grupo Passa Dois, Permiano, Bacia do Paraná) no furo de sondagem FP-01PR (Sapopema, PR). 2004. 117 f. Dissertação (Mestrado) -Instituto de Geociências e Ciências Exatas, UNESP, Rio Claro, 2004.

LIU, K. W.; GREYLING, E. H. Grain-size distribution and cementation of the Cretaceous Mzamba Formation of Eastern Cape, South Africa: a case study of a storminfluenced offshore sequence. Sedimentary Geology, v. 107, p. 83-97, 1996.

LOURENÇO, A. T. A. As formações Serra Alta, Teresina e Rio do Rasto (Grupo Passa Dois, Bacia do Paraná, Permiano) na região de Sapopema - São Jerônimo da Serra, PR. 2003. 87 f.Trabalho de Conclusão de Curso, Instituto de Geociências e Ciências Exatas, UNESP, Rio Claro, 2003.

MEGLHIORATTI, T. Estratigrafia do Grupo Passa Dois na região de Sapopema-Congonhinhas/PR (Permiano, Bacia do Paraná). 2005. 64 f. Trabalho de Conclusão de Curso, Instituto de Geociências e Ciências Exatas, UNESP, Rio Claro, 2005.

MEGLHIORATTI, T. Estratigrafia de seqüências das formações Serra Alta, Teresina e Rio do Rasto (Permiano, Bacia do Paraná) na porção nordeste do Paraná e centrosul de São Paulo. 2006. 132 f. Dissertação (Mestrado) Instituto de Geociências e Ciências Exatas, Universidade Estadual Paulista, Rio Claro, 2006.

MENDES, J. C. A Formação Corumbataí na região do Rio Corumbataí (estratigrafia e descrição dos lamelibrânquios). 
Boletim da Faculdade de Filosofia Ciências e Letras. Série Geologia, v. 145, n. 8, p. 1-119, 1952.

MENDES, J. C. Lamelibrânquios permianos do oólito de Angatuba, Estado de São Paulo; Formação Corumbataí São Paulo, Boletim da Saciedade Brasileira de Geologia, v. 11, n. 1, p. 37-56, 1962.

MOUNT, J. F.; KIDDER, D. Combined flow origin of edgewise intraclast conglomerates: Sellick Hill Formation (Lower Cambrian), South Australia. Sedimentology, v. 40, p. 315-329, 1993.

NEVES, J. P. Tafonomia de rochas carbonáticas conchíferas das formações Teresina e Rio do Rasto (Permiano, Bacia do Paraná). 2009. 89 f. (Dissertação) - Mestrado, Instituto de Geociências e Ciências Exatas, UNESP, Rio Claro, 2009.

NEVES, J. P.; ROHN, R.; SIMÕES, M. G. Tafonomia de Biválvios em Calcários Oolíticos da Formação Teresina (Bacia do Paraná, Permiano Médio, Prudentópolis, PR). Geologia USP: Série Científica, v. 10, n. 3, p. 19-36, 2010.

NG, C. Estromatólitos do Grupo Passa Dois, Permiano da Bacia do Paraná, Norte do Estado do Paraná e Sul do Estado de São Paulo. 2010. 84 f. Trabalho de Conclusão do Curso de Graduação em Geologia, Universidade Estadual Paulista, Instituto de Geociências e Ciências Exatas, Rio Claro, 2010.

PETRI, S.; COIMBRA, A. M., Estruturas sedimentares das Formações Irati e Estrada Nova (Permiano) e sua contribuição para a elucidação dos seus paleoambientes geradores, In: CONGRESSO LATINO-AMERICANO DE GEOLOGIA, 5., 1982, Buenos Aires. Actas... Buenos Aires, 1982, v. 2, p. 353-371.

PÖPPELREITER, M.; AIGNER, T. Unconventional pattern of reservoir facies distribution in epeiric successions: Lessons from an outcrop analog (Lower Keuper, Germany). A.A.P.G. Bulletin, v. 87, n. 1, p. 39-70, 2005.

RADLEY, J. D.; BARKER, M. J. Palaeoenvironmental significance of storm coquinas in a Lower Cretaceous coastal lagoonal succession (Vectis Formation, Isle of Wight, southern England). Geological Magazine, v. 137, n. 2 , p. $193-205,2000$.

RANGEL, C. V. G. T. Estudo paleoambiental dos carbonatos do albiano superior na Bacia de Sergipe- uma abordagem faciológica. 2002. 133 f. Dissertação (Mestrado) - Universidade Estadual do Rio de Janeiro, Rio de Janeiro, 2002.

ROHN, R. Evolução Ambiental da Bacia do Paraná durante o Neopermiano no leste de Santa Catarina e do Paraná. 1994. 2 v. Tese (Doutorado em Geologia Sedimentar) - Instituto de Geociências, Universidade de São Paulo, São Paulo, 1994.

ROHN, R. A estratigrafia da Formação Teresina (Permiano, Bacia do Paraná) de acordo com furos de sondagem entre Anhembi (SP) e Ortigueira (PR). In: MELO, J. H. G.; TERRA, G. J. S. (Ed.). Correlação de seqüências Paleozóicas Sul-Americanas. Ciência-Técnica-Petróleo. Seção: Exploração de Petróleo, v. 20, p. 209-218. 2001.

ROHN, R. The Passa Dois Group (Paraná Basin, Permian): Investigations in progress. In: WORKSHOP - PROBLEMS IN THE WESTERN GONDWANA GEOLOGY, SOUTH AMERICA - AFRICA CORRELATIONS: Du Toit revisited, 2007. Gramado. Extended Abstracts... Porto Alegre: UFRG, 2007. v. 1, p. 151-157.

ROHN, R.; FAIRCHILD, T. Estromatólitos Permianos em calcário coquinóide do Grupo Passa Dois, Nordeste do Paraná. Anais da Academia Brasileira de Ciências, v. 58, n. 3, p. 433-444, 1986.

ROHN, R.; LOURENÇO, A. T. A.; MEGLHIORATTI, T. As formações Serra Alta, Teresina e Rio do Rasto no furo de sondagem SP-23-PR (Permiano, Grupo Passa Dois, Borda Leste da Bacia do Paraná). In: CONGRESSO BRASILEIRO DE P e D EM PETRÓLEO E GÁS, 2003, Rio de Janeiro. Resumos... Rio de Janeiro: UFRJ/ Petrobras, 2003, p. 40-41.

RÖSLER, O. Novo afloramento fossilífero (Rio Preto) da Formação Teresina (Permiano Superior) no Estado do Paraná. Anais da Academia Brasileira de Ciências, v. 54, n. 1, p. 252, 1982.

RUNNEGAR, B.; NEWELL, N. D. Caspian-like relict molluscan fauna in South American Permian. Bulletin of American Museum of Natural History, Nova York, v. 146, p. 1-66, 1971.

SANER, S.; BABALOLA, L. O.; ABDULGHANI, W. M. Overburden compaction and pseudo-micritization; the most effective pore-deteriorating processes in the carbonate reservoirs. In: AAPG - ANNUAL CONVENTION, 2005, Calgary. Abstracts... Calgary: AAPG, 2005, 14 A122. 
SIMÕES, M. G.; KOWALEWSKI, M. Shell beds as paleoecological puzzles: a case study from the Upper Permian on the Paraná Basin, Brazil. Fácies, Erlangen, v. 38, p. 175-196, 1998.

SIMÕES, M. G.; ROCHA-CAMPOS, A. C.; ANELLI, L. E. Paleoecology and evolution of Permian pelecypod assemblages (Paraná Basin) from Brazil. In: JOHNSTON, P. A.; HAGGART, J. W. Bivalves - an Eon of evolution - Paleobiological studies honoring Norman D. Newell. Calgary: University of Calgary Press, 1998. p. 443-452.

SIMÕES, M. G.; GHILARDI, R. P. Protocolo tafonômico/ paleoautoecologico como ferramenta na análise paleossinecológica. Pesquisas em Geociências, Porto Alegre, v. 27, n. 2, p. 3-13, 2000.

SIMÕES, M. G.; TORELLO, F. F. Modelo de tafofácies para os moluscos bivalves do Grupo Passa Dois (Formações Serra Alta, Teresina e Corumbataí), Permiano Superior, Bacia do Paraná, Brasil. Revista Brasileira de Geociências, v. 33, n. 3, p. 1-10, 2003.

SIMÕES, M. G.; TORELLO, F. F.; ROCHA-CAMPOS, A. C. Gênese e classificação da coquina de Camaquã, Formação de Corumbataí (Neopermiano), na Região de Rio Claro, SP. Anais da Academia Brasileira de Ciências, São Paulo, v. 68, n. 4, p. 545-557, 1996.

SIMÕES, M. G.; ANELLI, L. E.; DAVID, J. M. Othonella araguaiana (Bivalvia, Megadesmidae) from the Corumbataí Formation(Midlle Permian), Eastern Margin of the Paraná Basin: systematic, Evolutionary and Biostratigraphic Significances. Geologia USP: Série Científica, v. 10, n. 2, p. 45-55, 2010.

SOUSA, S. H. de M.; SUGUIO, K.; CASTRO, J. C. Sedimentary facies of the Estrada Nova and Corumbataí Formations (Late Paleozoic of the Paraná Basin) in the State of São Paulo, Brazil. In: INTERNATIONAL GONDWANA SYMPOSIUM, 7., 1991. São Paulo. Proceedings... São Paulo: USP, 1991, p. 161-172.

TAVARES, T. M. V.; ROHN, R. First record of petrified Permian pecopterids from the Paraná Basin, Brazil (Corumbataí Formation, Passa Dois Group, northeastern State of São Paulo): morphology, anatomy and paleoecological implications. Journal of South American Earth Sciences, v. 27, n. 1, p. 60-73, 2009.

TUCKER, M. E. Sedimentary Petrology : an introduction to the origin of sedimentary rocks. 3 ed. Oxford: Blackwell, 1992. $252 \mathrm{p}$.
TUCKER, M. E.; WRIGHT, V. P. Carbonate sedimentology. Oxford: Blackwell Scientific, 1990. 482 p.

VIEREK, A. Source and depositional processes of coarsegrained limestone event beds in Frasnian slope deposits (Kostomoty-Mogiki quarry, Holy Cross Mountains, Poland). Geologos, v. 16, n. 3, p. 153-168, 2010.

WALKER, R. G.; PLINT, A. G. Wave- and stormdominated shallow marine systems. In: R. G. WALKER; N. P. JAMES (Ed.). Facies models response to sea level change. Geological Association of Canada, 1992. p. 219-238. 